\title{
The Use Of Deep Learning Strategies In Online Business Courses To Impact Student Retention
}

Pam Jones DeLotell, MBA, Kaplan University, USA

Loretta A. Millam, MBA, Kaplan University, USA

Michelle M. Reinhardt, MA, Kaplan University, USA

\begin{abstract}
Interest, application and understanding-these are key elements in successful online classroom experiences and all part of what is commonly referred to as deep learning. Deep learning occurs when students are able to connect with course topics, find value in them and see how to apply them to real-world situations. Asynchronous discussion forums in business courses offer excellent opportunities for instructors to promote deep learning and, thereby, positively impact retention rates. Instructional strategies that encourage deeper thought and further consideration of course topics not only lead to robust discussions but also to heightened student interest and motivation levels. This paper presents a review of deep learning strategies, explains how they can be successfully incorporated into asynchronous course discussions and highlights several critical connections between deep learning and increased student retention.
\end{abstract}

Keywords: Deep Learning; Online Education; Instructional Strategies; Student Retention

\section{INTRODUCTION}

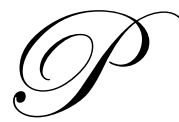

roviding students with a meaningful and lasting learning experience is just as critical in today's stateof-the-art online learning environments as it has been throughout the history of higher education. With the growing popularity of online learning, there has been an influx of literature related to effective online teaching and learning practices, much of it focusing on the value of deep or "significant learning" strategies (Fink, 2003). This paper will present a review of deep learning strategies, explain how they can be successfully incorporated into asynchronous course discussions and highlight several reasons why there is a critical connection between deep learning and increased student retention.

\section{CORE ELEMENTS OF DEEP LEARNING}

The concept of deep learning, frequently attributed to the early and later work of Martin and Saljo (1976; 1997), is based on a direct and meaningful connection between students and course information. Several more recent studies further suggest that deep learning involves a variety of learner-centered approaches that are designed to encourage students to use higher order thinking skills and to work directly with information, thus promoting deeper, more significant levels of understanding (Fink, 2003; Floyd, Harrington \& Santiago, 2009; Majeski \& Stover, 2007). Fink's theory of significant learning (2003), which is based on the following interactive taxonomy, provides a clear overview of six critical categories of deep learning;

- $\quad$ Foundational knowledge: Understanding concepts or terms

- $\quad$ Application: Solving problems or making decisions

- Integration: Making connections

- Human dimension: Relating knowledge gained to self and others

- $\quad$ Caring: Developing new ways of looking at the world

- $\quad$ Learning how to learn: Incorporating elements of critical thinking into the learning process 
Fink stressed the interactive nature of the six categories (2003) and suggested that this interactivity is a critical element of deep or significant learning because it promotes an educational experience that engages students on many different levels, thereby leading to the creation of knowledge that is meaningful, lasting and applicable to real-world situations. The more exposure students have to the different categories of learning and the more opportunities they have to participate in a variety of learner-centered activities, the more they will gain and the more value they will associate with the educational experience (Fink, 2007; Floyd, Harrington \& Santiago, 2009).

Weigel (2001) suggested clear ties between deep learning and constructivism, the learning theory that advocates knowledge not as something given to students but as something constructed by students as they are given opportunities to engage in realistic problem-solving or decision-making activities. Deep learning occurs when students are actively involved in the learning process and given opportunities to construct meaning, tie course concepts to personal experience and utilize problem-solving skills (Weigel 2001; Havard, Du \& Olinzock; Hacker \& Niederhauser, 2000). Interactions between students and instructors as well as overall student engagement in the learning process (Rosie, 2000), in fact, are at the core of deep learning and, therefore, instructional strategies that encourage thinking, questioning, problem-solving, decision-making, exploration, reflection, application and integration are all critical to this learner-centered approach (Ngeow \& Kong, 2003).

Additionally, Nelson Laird, Shoup, Kuh and Schwartz (2008) distinguished deep learning approaches from surface learning approaches, insisting that deep learning approaches result in superior student engagement, satisfaction and understanding. Atherton (2010) also noted that deep learning can often be equated with internal motivation, while surface learning quite often stems from external motivation. Students quite frequently utilize both levels of learning (Altherton, 2010), applying surface-level skills at the foundational level (Fink, 2003; Floyd, Harrington \& Santiago 2009), where the accumulation of facts and memorization of relevant terms takes place, and relying upon higher order thinking and learning skills as they become more actively involved with information. As instructors encourage students to become more engaged in the learning process and move into the next five levels of the taxonomy (Fink, 2003), integration, synthesis, reflection as well as a more personal commitment to the learning process become the critical elements (Nelson Laird, Shoup, Kuh \& Schwartz, 2008). A basic difference between deep learning and surface learning stems from the fact that surface learning focuses on retaining facts and mastering terms, whereas deep learning focuses more on understanding and making connections (Draper, 2009). The more students are encouraged to move beyond surface level learning by being given opportunities to engage in the learning process through a variety of activities and prompts, the more they will gain in terms of increased levels of interest, understanding and motivation (Nelson Laird, Shoup, Kuh \& Schwartz, 2008).

Research clearly suggests that deep learning strategies promote long-term knowledge retention, personal growth and understanding. Education is a field where continued learning is almost imperative in order to advance the core product, education. In recent years, technology has allowed education to take on a new paradigm of learning, one that is proving to represent a shift in the way students, particularly non-traditional students, prefer to learn yet at the same time is challenging for educators in terms of providing a deeper learning environment. This change in how people obtain an education has more to do with the busy schedules of working adults and far less to do with more academically-associated reasons (Battalio, 2007). Although perhaps not the primary goal of most online students, online learning environments within the business course arena offer unique and exciting possibilities for deep learning that may change not only what students get out of an online education, but why students choose that modality to meet educational needs.

\section{IMPLEMENTATION STRATEGIES}

So, what does it take to drive students toward deeper learning, particularly in online business courses? The process begins with the instructor. The instructor is at the center of the classroom experience and has the ability to encourage and motivate the student. A motivated student, in turn, is more likely to be a successful deep learner. Dennen and Wieland (2007) found in a recent study some support for the theory that when a classroom has a consistent facilitative instructor that brings in real world experience, encourages the students to expand on each other's posts and exhibits a productive social interaction without monopolizing the thread, the students are more apt to engage in the discussions. In this type of online discussion, the students are encouraged to offer their own experiences and opinions, while being prompted to dig deeper. By contrast, students being led by an instructor that 
offers little experience or guidance and is just present in the discussion threads are more apt to simply answer the questions with no in-depth discussion or thought. In this latter type of discussion thread the answers are similar and do not bring out new information. This type of classroom may produce surface learning, but very seldom reaches the deep learning capabilities (Dennen \& Wieland). Although deep learning core elements such as foundational knowledge may be realized, application, integration, human interaction and caring are most likely absent, resulting in a learning process that is anything but deep.

In order to achieve a meaningful discussion thread, the students need to be focused on a shared mission. Similar to any well-crafted corporate mission, students much clearly understand what the end goal is. Toward that end, students need well structured assignments such as answering a specific set of questions in order to initiate deep learning (Dennen \& Wieland, 2007). This does not preclude the use of open-ended questions, but there must be a clear purpose to the question that keeps all students within the discussion driving toward the same general assumptions and applications. Deep learning cannot and will not be achieved when students interpret the discussion question differently and are therefore not driving further discovery within a narrow scope.

Hacker and Niederhauser (2000) introduced five core actions to promote deep learning in an online classroom. These five actions included the following:

- $\quad$ Effective instructors require students to become active participants in their own learning by asking them to construct deep explanations, justifications, and reasons for what they think and do;

- $\quad$ Learning is grounded in the effective use of examples;

- $\quad$ Collaborative problem solving;

- $\quad$ Effective instruction uses feedback that is commensurate with performance; and

- $\quad$ Effective instruction has embedded within it motivational components that enhance self-efficacy and perceived challenge (Hacker \& Niederhauser, 2000).

There are several additional guidelines that instructors can follow to set the stage for the deep learning process.

- $\quad$ Setting clear expectations which include examples of a great post will guide students in the right direction.

- $\quad$ Posting first in each discussion thread which sets the pace and allows the opportunity to bring in related mini-topics.

- Offering positive reinforcement and if necessary guiding students into another direction with a question prompt.

- $\quad$ Staying present in the discussion thread throughout the week and responding quickly to questions.

- $\quad$ Sharing instructor specific experiences and how they relate to the current topic helps the student tie the discussion to individual experience and usefulness.

- $\quad$ Making the topic real for the students through current examples and application.

- $\quad$ Offering additional information, web sites, or links about the topic to encourage additional reading or research. (Sull, 2009)

Felder (n.d.) detailed five conditions that are shown to increase the opportunity that students will develop a deep learning approach to learning. Student-perceived relevance of the subject matter applies when the student knows how the material relates to them personally. Many students do not have the experience to analyze problems in detail. Clearly stated instructional objectives are needed along with specific examples. Allow the students the opportunity to practice. A well defined discussion thread question will prompt the student to answer a question or solve an issue or problem in detail. The instructor should follow up with detailed constructive feedback. Appropriate level tests should be administered that encourages deep analysis. Open ended questions allow the student to express their ideas and understanding thoroughly. The assignments should be a reasonable workload. The number of discussion threads should be equivalent to the level of the student. If applicable and the course content permits, it is beneficial to allow the student the opportunity of alternative discussion threads depending on their individual interests. 
The following examples will illustrate different ways in which instructors might incorporate Felder's (n.d.) conditions into the discussion area of an introductory business course. First, in an effort to establish the relevance of a discussion focusing on job security versus pay and benefits, the instructor might encourage students to explain in detail their reasoning on why one or the other is more important to them. There is no right answer as far as which is more important, but this question would prompt a debate that would require the students to know and understand the facts to support their decision. Second, the instructor might prompt students to answer a question or solve an issue or problem in detail by using a scenario that requires the students to determine whether an organization needs a manager or a leader. Third, constructive feedback can also be used to further promote deep learning in a discussion where students are asked to comment on the benefits and challenges of virtual teams. The instructor might explain to a student that his response regarding the benefits of virtual teams incorporated many relevant examples, yet the section focused on the challenges needs further development and support. In this way, the student would have a sense of the strengths and weaknesses of his posting and a clear direction for further development. Finally, once students have had time to reflect upon and respond to the initial discussion topic, the instructor might post an enrichment question or resource that would provide students with the opportunity to further explore the topic and share their thoughts.

Additional research by Doyle (2009) detailed several activities that may promote students' ability to achieve deep learning particularly in relation to business courses, where soft skills typically require a greater ability of students to make the connections between different topics and subject matter.

- $\quad$ Problem-based learning. Students are given a discussion thread question that relates to a real world issue or problem. The students are to gather information, explain their findings, and come to a solution utilizing decision making processes.

- $\quad$ Case-based learning. Actual case studies set up the scenario for the discussion question that requires the students to analyze the details and respond with their results.

- $\quad$ Student research. A discussion question can prompt a student to research a specific topic. They are able to inquire, interpret or revise facts to present their own understanding while explaining it to others through their responses.

Of course, the ultimate goal of each of these strategies is to drive a deeper learning process within online business courses, thereby engaging students in the learning process and ultimately improving retention. Although millions of students have enrolled in online courses and that number seems to be increasing over time, a significant number of those enrolled do not complete the program for which they originally enrolled. Although many issues could be the cause of that reduced retention, there is also a clear and compelling argument that retention is impacted by student engagement in the course, and student engagement in the course is enhanced through deep learning strategies.

\section{RETAINING ONLINE STUDENTS IN THE CURRENT ENVIRONMENT}

Online education is continuing to gain popularity not only in terms of the number of exclusively online distance education providers, but also in terms of traditional brick and mortar institutions offering some portion of a program through distance education (Dooley \& Wickersham, 2002). Increasingly, literature supports the notion that technology has allowed education to take on a new paradigm of learning. Indeed, education is a field where continual learning is imperative for the advancement of the very product that educators produce. This relatively new venue into online education is not without issues however. Perhaps one of the more significant issues inherent in many online programs is concern over retention rates which, at this time, do not mirror those of traditional online universities. Recent legislation also clearly indicates that both graduation rates and retention rates at for-profit online institutions will play important roles in determining financing access for many historically non-traditional and disadvantaged students (United States: Monsters in the making, 2010).

In the wake of this proposed legislation, educational leaders are increasingly challenging colleges and universities to improve access, to enhance student learning, and to increase graduation rates (Finnegan, Morris, \& Lee, 2008). Lassiter (2009) noted retention rates in online programs range from 50 to 80 percent, which is far less than the 80 to 90 percent retention rates often seen in traditional colleges and universities. In 2006, graduation rates 
at virtual colleges and universities ranged anywhere from 26 percent to 87 percent, clearly an average which indicates that not all students are finding value and applicability in the courses or curriculum (Finnegan et al.). Assuming the essential content and course parameters are equal within the two modalities, something about distance education itself must therefore be creating the retention differences. While there is significant literature that explores overall retention at traditional universities, very little research exists which explores course level retention, particularly as it pertains to online colleges and universities. What research there is however shows that retention in online courses can be problematic (Diaz, 2002; Kemp, 2002). Although Andreu (2002) identified 20 variables that impact student retention in traditional colleges and universities and Kemp noted personal characteristics and life circumstances all impact persistence in online education, none of those variables address the causal relationship between lack of engagement, retention and online students. Garland (1993) and Powell, Conway and Ross. (1990) agreed students fail to persist in online education for many reasons, but central in most of the literature surrounding this subject is the notion that although personal characteristics and life changes impact student persistence in online courses, instructional quality and content are core components in determining student persistence within an online course.

Morris, Xu and Finnegan (2005) suggested that faculty behavior affects persistence within the online classroom. There is little doubt that online learning offers enormous flexibility for the new paradigm of student. There are however several barriers to learning that impact online students. Although online learning provides flexibility, online learning also required both self-direction and motivation (Havard, Du, \& Olinzock, 2005). Some students report personal, family and technological issues as the reason for failure to complete a program or course online and still other students cite weak curriculum, lack of connection to the material and lack of faculty student interaction as primary reasons for not completing courses or programs (Powell, et al., 1990). The self-direction, motivation and deep learning required to engage a student within the online classroom can be fostered however. Crissman (2001) found that both peer and faculty support seemed to be key in fostering student learning. Crissman also found that although course curriculum and content are important in driving a deeper learning process, the collaboration amongst students and instructors is what drives the learning process. Garrison, Anderson and Archer (2001) found a connection between student and faculty interaction and the learning process and postulated that a link exists between critical thinking, social interaction and deep learning. Havard et al. also found that online learning can "support critical thinking and deep learning, as it provides a learner-centered environment and allows time for learners to reflect and respond to issues being discussed" (p.3). In a similar way, deep learning involves a transformational perspective and this transformation may ultimately lead to further engagement on the part of the online student, thus improving retention rates (Roberts \& Roberts, 2008).

Drouin (2008) furthered this notion of connecting the engagement of students within the classroom, furthered by deep learning strategies to retention rates and postulated that both social construction of knowledge and social presence and community impact student satisfaction and therefore student retention within an online course. In turn, social learning theory tells us that active learning requires an exchange of information with others. The deeper the learning process therefore, the more likely students are to engage in and complete a course. This link between student satisfaction and retention has already been established in the literature, and student satisfaction has also been found to be impacted by issues such as quality of instruction and perceived quality of course materials (Rovati, 2005; Liu, Gomez, Khan, \& Yen, 2007).

\section{CONCLUSION}

The key to both retaining the online student and driving deep learning within the online environment may therefore boil down to student engagement. Literature shows that student engagement is often a product of instructional content and quality across the social interactions which occur on discussion boards within online courses. Although most online business courses are interactive to some extent, the quality of that interaction varies significantly across both courses and institutions. Particularly in the business course environment where students are exposed to qualitative and quantitative information which need to be processed and understood differently, using discussion forums to drive engagement will be key to getting students interested and setting the stage for deeper learning as the class progresses. Problem and case-based learning are both effective in terms of content areas which should be the focus of curriculum development, but also key in this equation are the interactive discussions which must occur within the course in order to drive the deep learning that should be the focus of online business courses. 
There is arguably no better place to practice the concepts of deep learning than the online classroom since the modality itself lends to more comprehensive and well-thought out responses. Through the use of questioning skills, constructive feedback and a focus on the relevance of the topics in discussions, online faculty and online institutions as a whole can ensure that that they are not only driving student learning but also creating conditions that will foster deeper, more fulfilling learning. This deep learning, in turn, will ultimately positively influence both student satisfaction rates and student retention rates.

\section{AUTHOR INFORMATION}

Pam Jones DeLotell joined Kaplan University in 2005 and currently serves as a Department Chair for the Management Division in Kaplan's School of Business and Management. Pam has 30 years of management experience in higher education in both a traditional on-ground and non-traditional online setting and has also served as Associate Professor of Management at a traditional private institution. Pam has an undergraduate degree from Loyola Marymount University, an MBA from Lindenwood University and is currently at work on a Ph.D. in Organizational Leadership. Pam's current research interests include the areas of organizational culture and leadership and online pedagogy.

Michelle Reinhardt joined Kaplan University as a full-time instructor in 2003 and currently serves as a Department Chair in the school of Business \& Management. Michelle has over 20 years of combined online and traditional classroom teaching experience and has designed courses and conducted online faculty workshops as well. Michelle holds a Masters Degree in Communication Arts/English from Western State College and is pursuing an MBA at Kaplan University. Her current research interests are in the areas of student learning and engagement and mentoring as a critical resource for women seeking management positions in higher education and business.

Loretta "Laurie" Millam joined Kaplan University in 2002 and currently serves as a Department Chair in the School of Business and Management. She has over 10 years combined experience in education. Prior to entering the education field, Loretta worked in Business Management for over 11 years. Loretta holds a MBA from St. Ambrose University in Davenport, Iowa. She is currently pursuing a Ph.D. in Education with an emphasis in Higher Education Leadership at NorthCentral University in Prescott Valley, Arizona. Loretta's current research interests are in the areas of student success and learning strategies specifically for first term students.

\section{REFERENCES}

1. Andreu, M. (2002). Developing and implementing local-level retention studies: A challenge for community college institutional researchers. Community College Journal of Research and Practice, 26(4), 333-344.

2. Atherton, J. (2010, February). Learning and teaching: Deep and surface learning. Retrieved from http://www.learningandteaching.info/learning/deepsurf.htm

3. Battalio, J. (2007). Interaction online: A re-evaluation. Quarterly Review of Distance Education, 8(4), 339352.

4. Crissman, J. (2002). The impact of clustering first year seminars with English composition courses on new students' retention rates. Journal of College Student Retention, 3(2), 137-152.

5. Dennen, V., \& Wieland, K. (2007). Facilitating online group discourse processes. Distance Education, 28(3), 281-298.

6. Diaz, D. (2002, May/June). Online drop rate revisited. The Technology Source. Retrieved from http://technologysource.org/article/online drop_rates revisited/

7. Dooley, K., \& Wickersham, L. (2007). Distraction, domination, and disconnection in whole-class online discussions. Quarterly Review of Distance Education, 8(1), 1-8,87,89.

8. Doyle, T. (n.d.). Promoting deep learning in college students. Retrieved from http://www.scribd.com/doc/12761431/Promoting-Deep-Learning-in-College-Students

9. Draper, S. W. (2009). Catalytic assessment: Understanding how MCQs and EVS can foster deep learning. British Journal of Educational Technology, 40(2), 285-293.

10. Drouin, M. (2008). The relationship between students' perceived sense of community and satisfaction, achievement, and retention in an online course. Quarterly Review of Distance Education, 9(3), 267-284. 
11. Felder, R., (n.d). 5 Ways to promote deep learning. Chemical Engineering Education, Retrieved from http://www.oncourseworkshop.com/Learning024.htm

12. Fink, L. D. (2003). Creating significant learning experiences: An integrated approach to designing college courses. San Francisco, CA: Jossey-Bass.

13. Fink, L. D. (2007). The power of course design to increase student engagement and learning. Peer Review 9(1), 13-17.

14. Finnegan, C., Morris, L., \& Lee, K. (2008). Differences by course discipline on student behavior, persistence, and achievement in online courses of undergraduate general education. Journal of College Student Retention, 10(1), 39-54.

15. Floyd, K., Harrington, S. \& Santiago, J. (2009). The effect of engagement and perceived course value on deep and surface learning strategies. Informing Science: the International Journal of an Emerging Transdiscipline, 12, 181-190.

16. Garland, M. R. (1993). Student perceptions of the situational, institutional, dispositional, and epistemological barriers to persistence. Distance Education, 74(2), 181-198.

17. Garrison, D. R., Anderson, T., \& Archer, W. (2001). Critical thinking, cognitive presence, and computer conferencing in distance education. The American Journal of Distance Education, 15(1), 7-15.

18. Hacker, D. \& Niederhauer, D. (2000). Promoting deep and durable learning in the online classroom. New Dimensions for Teaching and Learning, 84, 53-63.

19. Havard, B., Du, J. \& Olinzock, A. (2005). Deep Learning: The knowledge, methods, and cognitive process in instructor-led online discussion. Quarterly Review of Distance Education, 6(2), 125-135.

20. Kemp, W. (2002). Persistence of adult learners in distance education. American Journal of Distance Education, 16(2), 65.

21. Lassitter, S. (2009). Establishing a relationship between virtual instructor and student in the online classroom. Distance Learning, 6(1), 53-57.

22. Liu, S., Gomez, J., Khan, B., \& Yen, C. (2007). Toward a Learner-Oriented Community College Online Course Dropout Framework. International Journal on ELearning, 6(4), 519-542.

23. Majeski, R. \& Stover, M. (2007). Theoretically based pedagogical strategies leading to deep learning in asynchronous online gerontology courses. Educational Gerontology, 33, 171-185.

24. Marton, F., \& Saljo, R. (1997). Approaches to learning, In: F. Marton, D. Hounsell, \& N. Entwistle (Eds) The experience of learning: Implications for teaching and studying in higher education. $3^{\text {rd }}$ (Internet) edition. Edinburgh: University of Edinburgh, Centre for Teaching, Learning and Assessment. pp. 39-58.

25. Marton, F., \& Saljo, R. (1976). On qualitative differences in learning: I. Outcome and process. British Journal of Educational Psychology, 46, 4-11.

26. Morris, L. V., Xu, H., \& Finnegan, C. (2005). Roles of faculty in teaching asynchronous undergraduate courses. The Journal of Asynchronous Learning Network, 9(1), 65-82.

27. Nelson Laird, T.F., Shoup, R. Kuh, G. D. \& Schwartz, M. J. (2008). The effects of discipline on deep approaches to student learning and college outcomes. Research in Higher Education, 49, 469-494.

28. Ngeow, K.\& Kong, Y. (2003). Learning through discussion: Designing tasks for critical inquiry and reflective learning. Retrieved from ERIC database. (ED477611)

29. Powell, R., Conway, D., \& Ross, L. (1990). Effects of student predisposing characteristics on student success. Journal of Distance Education, 5(1), 5-19.

30. Roberts, J., \& Roberts, K. (2008). Deep reading, cost/benefit, and the construction of meaning: Enhancing reading comprehension and deep learning in sociology courses. Teaching Sociology, 36(2), 125-140.

31. Rosie, A. (2000). Online pedagogies and the promotion of "deep learning." Information Services \& Use, 20 (2/3), 109-116.

32. Rovai, A., \& Whiting, M. (2005). Feelings of alienation and community among higher education students in a virtual classroom. Internet and Higher Education, 8, 97-110.

33. Sull, E., (2009). The (almost) complete guide to effectively managing threaded discussions. Distance Learning, 6(4), 65-70.

34. United States: Monsters in the making? For-profit colleges. (2010, July). The Economist, 396(8692), 36.

35. Weigel, V. (2001). Deep learning for a digital age: Technology's untapped potential to enrich higher education. San Francisco, CA: Jossey-Bass. 
NOTES 